\title{
Low energy helium ion irradiation induced nanostructure formation on tungsten surface
}

\author{
A. Al-Ajlony ${ }^{1 \mathrm{a}}$, J. K. Tripathi ${ }^{\mathrm{b}}$, and A. Hassanein ${ }^{\mathrm{b}}$ \\ ${ }^{a}$ Department of Materials Engineering, Al-Balqa Applied University, As-Salt, Jordan \\ ${ }^{\mathrm{b}}$ Center for Materials Under Extreme Environment (CMUXE), School of Nuclear \\ Engineering, Purdue University, West Lafayette, Indiana 47907, USA
}

\begin{abstract}
We report on the low energy helium ion irradiation induced surface morphology changes on tungsten (W) surfaces under extreme conditions. Surface morphology changes on W surfaces were monitored as a function of helium ion energy $(140-300 \mathrm{eV})$, fluence $\left(2.3 \times 10^{24}-1.6 \times\right.$ $10^{25}$ ions $\left.\mathrm{m}^{-2}\right)$, and flux $\left(2.0 \times 10^{20}-5.5 \times 10^{20}\right.$ ion $\left.\mathrm{m}^{-2} \mathrm{~s}^{-1}\right)$. All the experiments were performed at $900^{\circ}$ C. Our study shows significant effect of all the three ion irradiation parameters (ion flux, fluence, and energy) on the surface morphology. However, the effect of ion flux is more pronounced. Variation of helium ion fluence allows to capture the very early stages of fuzz growth. The observed fuzz growth and morphology changes were understood in the realm of various possible phenomena. The study has relevance and important impact in the current and future nuclear fusion applications.
\end{abstract}

\section{Introduction}

Tungsten (W) is currently the most promising candidate materials to serve as a plasma-facing component (PFC) in future fusion devices [1]. In addition to its higher melting point, W has good thermal conductivity and lower sputtering yield when bombarded by energetic light ions such as Helium $(\mathrm{He})$ and Hydrogen $(\mathrm{H})$ isotopes $[1,2]$. Moreover, W has shown low $\mathrm{H}$ isotopes

\footnotetext{
${ }^{1}$ Corresponding author: montaserajlony@yahoo.com
} 
retention characteristics compared to other PFC candidate materials[3]. On the other hand, W being a high-Z element is not favorable to be mixed with the DT plasma. Contamination of high$\mathrm{Z}$ materials in the plasma can enhance the plasma radiative heat loss considerably, leading to a significant reduction in confinement time or even plasma quenching at certain contamination levels [4]. The importance of studying the behavior of $\mathrm{W}$-radiation interaction rises from this important point. Many research groups around the world have performed a wide variety of experiments on $\mathrm{W}$ response to conditions similar to fusion reactor environments. Most of these studies have investigated the response of $\mathrm{W}$ exposed to high fluxes of He, deuterium (D) or He/D plasmas [2, 5-10]. In fusion reactors, including ITER (International Thermonuclear Experimental Reactor) and DEMO (DEMOnstration Power Station), PFCs including W are exposed to high fluences of low-energy $\mathrm{He}^{+}$ions $[6,11,12]$, which motivates performing these experiments.

A common conclusion among all recent studies is the fact, that $\mathrm{W}$ surface, under high fluxes of He plasma exposure, can form very fine nanostructures (nano-fibers) or "fuzz" $[2,6,9,11]$. W fuzz can grow to high thicknesses (as thick as few $\mu \mathrm{m}$ ) on the top of the original W surface [6]. W-fuzz is a very fragile structure that can be detached from W surface during sudden stress or high-heat loads $[13,14]$. The fuzz formation is unfavorable scenario where $\mathrm{W}$ fuzz may develop during the early stages of normal operations of future fusion devices [8, 13] and could severely affect the PFC performance. This specially formed structure was found to occur in most of the different grades of $\mathrm{W}$ and $\mathrm{W}$-alloys that are being considered in future devices [6]. Fuzzy $\mathrm{W}$ surface can be a significant source of W (high-Z) dust particles which can pose a serious threat for the sustainability of a stable fusion reaction $[15,16]$. Therefore, minimizing the possibility of formation of high-Z dust is a priority in PFC material selection [16]. In fact, many transient events due to plasma instability such as ELMs and disruptions can create enough stresses and thermal loads to break or easily remove the $\mathrm{W}$ fuzz [17]. Therefore, contamination of plasma due 
to the presence of fuzzy $\mathrm{W}$ surfaces is always a serious concern $[8,13,18]$. Additionally, the presence of $\mathrm{W}$ fuzz on a $\mathrm{W}$ surface may alter and significantly degrade the $\mathrm{W}$ thermal properties [17].

To the date, researchers have concluded that the major factors significantly influence the W fuzz growth are surface temperature, incident He ion-energy, -flux, and -fluence[18]. The lower energy threshold for fuzz growth is 12 to $30 \mathrm{eV}[2,19,20]$ depending up on sample grade, plasma conditions, and surface temperature used during the experiments. The fuzz growth also has the lower $(\sim 900 \mathrm{~K})$ and upper $(\sim 2000 \mathrm{~K})$ temperature thresholds, referred as "temperature window". In general, below $900 \mathrm{~K}$ pits and blisters appearance were observed. The studies performed by Wright et al. is also relevant in where they have observed $\mathrm{W}$ nano-tendrils in the divertor region of a high-power density tokamak experiment [21]. In addition to this, a series of experiments have been performed extensively on high- $Z$ and high-melting point materials in tokamak environment and/or in laboratory plasma accelerator systems, using comparatively low energy $\mathrm{H}$ and He ions[5, 22-27]. However, the physical mechanisms responsible for such growth are not yet very clear [5]. Although most of the reported fuzz formation cases happened when the surface is bombarded by $\mathrm{He}^{+}$ions having lower energy than the energy required for displacing the target atoms $[5,6,28]$, a considerable surface modification was not seen. Many researchers believe that the reason behind the fuzz formation is mainly due to the role of He bubbles that form just beneath the surface [2, 29-31]. The formation and the growth of these bubbles were widely reported in many TEM studies [32-34]. He bubbles formation and growth in W due to $\mathrm{He}^{+}$ion irradiation occurs via two main scenarios. The first is when the $\mathrm{He}^{+}$ion energy is greater than the energy required to displace the $\mathrm{W}$ atoms from their lattice sites. In this case, along with the high percentage of solute He atoms in the $\mathrm{W}$ matrix, a considerable amount of point defects in the original $\mathrm{W}$ lattice, is formed. These point defects include short lived self-interstitials and 
relatively long-lived vacancies. A fraction of these point defects survives long enough to migrate and agglomerate to create larger two dimensional (2D) defects (such as a dislocation loops, caused by the agglomeration of interstitials) and 3D defects (such as voids, caused by the agglomeration of vacancies). The presence of voids will allow the He solutes to migrate freely into these voids. As a result of He accumulation in these voids, an internal He pressure can build up, leading to vacancies absorption in the process of void growth [35]. In this scenario the growth rate will depend solely on the rate of vacancies migration as well as on the internal $\mathrm{He}$ pressure inside these bubbles [35]. The second scenario is expected to occur in the case of low energy $\mathrm{He}^{+}$ions (lower than the energy required to cause atomic displacement). It is also the case for most of the recent experimental observations where the W-fuzz was reported after He plasma exposure $[5,6,28,36]$. In these cases, nano-scale He bubbles can be formed due to the migration of He atoms (solute) into preferred sites in the W lattice (such as dislocations, grain boundaries, and vacancies, etc.) $[30,37,38]$. The accumulation of $\mathrm{He}$ atoms in these site can build up an internal He pressure that is enough to make the newly nucleated bubbles to grow by emitting self-interstitials and dislocation loops $[38,39]$. The formation of He bubbles in this scenario is much more difficult than in the first one. In fact, one condition required for the growth of these He bubbles is that the internal He pressure inside these bubbles to be greater than the strain free energy associated with squeezing self-interstitials into the bubble's surrounding lattice. Moreover, the rate of self-interstitials emission determines the rate of the volumetric growth of the He bubbles. The mechanical strength of the surrounding $\mathrm{W}$ matrix is another factor which need to be considered where He bubbles are situated near the surface. Blistering occurs when the He bubble internal pressure is greater than the materials' mechanical strength that separates the He bubbles from the outer surface (bubble cap). Therefore, deformation, cracking, or even complete breakage of the cap materials are common blistering features [7, 40-42]. 
On the other hand, the increased $\mathrm{He}$ internal pressure inside these newly formed bubbles also promotes the backward migration of the He atoms from the bubbles to the W lattice [35]. Due to this fact, the internal pressure of He bubbles is expected to be maintained at a fixed value (at equilibrium) during the bubble growth process. The internal He equilibrium pressure is largely depends on the He concentration in bubble's surrounding lattice. Therefore, only appreciable $\mathrm{He}$ concentration in the matrix surrounding the He bubble will guarantee a forward migration of the $\mathrm{He}$ atoms into the bubble even at high bubble pressure. The maximum achievable He pressure will always be dictated by the He concentration in the bubble's surroundings and therefore the bubbles growth rate is also $\mathrm{He}$ concentration dependent. On the other hand, the flux of He ions during the bombardment governs the He concentration in the sample matrix. Also, the $\mathrm{He}$ concentration is expected to vary with depth. For these reasons the bubble formation is always preferred to occur near the irradiated surface [29] where the He concentration is maximum. The temperature of the sample is another important factor because it governs the energy of formation of self-interstitials in the $\mathrm{W}$ lattice and the rate of interstitial diffusion. Self-interstitial formation rate will be higher for a higher lattice temperature.

In this study, we focus on the evolutions and changes in the $\mathrm{W}$ surface morphology due to $\mathrm{He}^{+}$ ion irradiations having ion fluence $\left(2.3 \times 10^{24}-1.6 \times 10^{25}\right.$ ions $\left.^{-2}\right)$, ion flux $\left(2.0 \times 10^{20}-5.5 \times\right.$ $10^{20}$ ion $\left.\mathrm{m}^{-2} \mathrm{~s}^{-1}\right)$ and ion energy $(140-300 \mathrm{eV})$. Although a few studies have been performed on the similar topic with similar ion flux range, the uniqueness of our investigation is predicting and demonstrating the very early stage of the $\mathrm{W}$-fuzz structure formation, due to low energy $\mathrm{He}^{+}$ion beam irradiation at elevated temperature.

\section{Experimental methods}


The experiments were performed in the IMPACT (Interaction of Materials with Particles and Components Testing experimental) facility at the center for materials under extreme environment (CMUXE), Purdue University [43]. Several W samples of $10 \mathrm{~mm} \times 10 \mathrm{~mm}$ were cut from coldrolled W sheet having thickness of $0.5 \mathrm{~mm}$ with pure $(99.95 \% \mathrm{~W})$ samples. All W samples were mechanically polished to a mirror- finish. Each sample was sputter cleaned by $1 \mathrm{keV} \mathrm{Ar}^{+}$ion beam (current density $\sim 10 \mathrm{~mA} \mathrm{~cm}{ }^{-2}$ ) for 2 minutes at room temperature (RT). After that, each sample was heated to $900^{\circ} \mathrm{C}$ and irradiated at normal incidence. Ion irradiation experiments were performed in three different cases: as a function of (a) ion fluence $\left(2.3 \times 10^{24}-1.6 \times 10^{25}\right.$ ions $\mathrm{m}^{-}$ 2 ) at constant ion flux $\left(5.5 \times 10^{20}\right.$ ion $\left.^{-2} \mathrm{~s}^{-1}\right)$ and energy $(300 \mathrm{eV})$, (b) ion flux $\left(2.0 \times 10^{20}-5.5 \times\right.$ $10^{20}$ ion $\left.\mathrm{m}^{-2} \mathrm{~s}^{-1}\right)$ at constant ion fluence $\left(1.0 \times 10^{25}\right.$ ions $\mathrm{m}^{-2}$ and energy $(300 \mathrm{eV})$, and (c) ion energy $(140-300 \mathrm{eV})$ at constant ion flux $\left(5.5 \times 10^{20} \mathrm{ion}^{-2} \mathrm{~s}^{-1}\right)$ and fluence $\left(1.0 \times 10^{25}\right.$ ions $\mathrm{m}^{-}$ ${ }^{2}$ ). Both $\mathrm{Ar}$ (for surface cleaning) and He ions irradiations were performed using KRI-KDC-10 ion source that is attached to the irradiation chamber in IMPACT facility. The base pressure of the UHV chamber was $\sim 3.0 \times 10^{-9}$ torr, however the working pressure (during $\mathrm{He}^{+}$ion irradiation) was $1.0 \times 10^{-3}$ torr, which was kept constant for all experiments. In-situ X-ray photoelectron spectroscopy (XPS) was performed after the irradiation process to assure the purity of the ion irradiation processes. The XPS data analysis and chemical lines fitting were done using commercial CasaXPS software. All the XPS spectral line shapes were chosen to be asymmetrical Gaussian/Lorentzian sum formula and a Shirley background subtraction were performed. The effects of $\mathrm{He}^{+}$ion incident particle energy on the surface morphology evolution were studied by irradiating positively biased samples at various bias voltages. The surface morphology of the irradiated sample surfaces was evaluated using scanning electron microscopy "Hitachi S-4800 Field Emission SEM".

\section{Results and discussions}




\section{a. Effect of $\mathrm{He}^{+}$ion fluence}

The impact of the total $\mathrm{He}^{+}$ion fluence on the fuzz evolutions were studied by irradiating several W samples at a fixed ions flux $\left(5.5 \times 10^{20}\right.$ ion $\left.\mathrm{m}^{-2} \mathrm{~s}^{-1}\right)$ by varying irradiation time duration. All samples were heated during irradiation to a constant temperature of $900^{\circ} \mathrm{C}$. The first sample was irradiated for 70-minute achieving total fluence of $2.3 \times 10^{24}$ ions $\mathrm{m}^{-2}$. Figure 1(a) shows SEM image of the irradiated surface. All the SEM images shown in Fig. 1 were taken after tilting the sample at $52^{\circ}$. At this stage of irradiation tiny nano-features started to grow on the sample surface. It seems this stage is the very early stage of "fuzz formation" [2]. The second samples were irradiated at the same conditions for longer time duration (166 minute) for achieving the total fluence of $5.5 \times 10^{24}$ ions $\mathrm{m}^{-2}$. The irradiated surface is shown in Fig. 1(b). As it can be seen in this SEM image, the small nano-features have grown bigger and they started to have more irregular shapes. After that, another sample was irradiated with a higher $\mathrm{He}^{+}$ion fluence $(9.2$ $\times 10^{24}$ ions $\mathrm{m}^{-2}$ ) and the resulted surface morphology is shown in Fig. 1(c). The SEM images presented in this figure show a considerable vertical growth of previously noticed nano-features. The figure shows that the ion fluence enhancement causes denser and tangled fuzz evolutions. Furthermore, higher degree of vertical fuzz growth structure (Fig. 1 (d)) was observed on increasing ion irradiation time duration (for achieving He fluence of $1.6 \times 10^{25}$ ions $\mathrm{m}^{-2}$ ). Although the information shown in Fig. 1 is vital to demonstrate the vertical fuzz evolution of the observed nanostructure, a clear understanding of the evolution mechanism is yet to come. In another approach, we recorded the SEM images at $0^{\circ}$ sample tilt, for monitoring the changes in lateral evolution.

Figure 2 shows a comparison of the surface nanostructure appearances, due to $52^{\circ}$ sample tilting and without sample tilting $\left(0^{\circ}\right)$. The figure shows, the initial stage of $\mathrm{W}$ fuzz formation, for ion fluence of $2.3 \times 10^{24}$ ions $\mathrm{m}^{-2} \mathrm{He}^{+}$ion irradiation. In fact, Fig. 2(a) is a high magnification image 
from the region in Fig. 1(a), which shows nanostructure appearance on the surface. On the other hand, the $0^{\circ}$ case (without sample tilt) reveals the presence of a network of surface holes in between the nano-tendrils (Fig. 2(b)).

Figure 3 shows the SEM images from the same samples (as above, in Fig. 1 (a)) but with $0^{\circ}$ sample tilt and at higher magnifications. This part of the experiment was performed to show the lateral surface evolutions due to $\mathrm{He}^{+}$ion irradiations in extreme conditions, which may not appear in the case of titled $\left(52^{\circ}\right)$ samples. Figure 3 clearly demonstrates the appearance of nanoscopic hole (pinholes) networks between the surface nano-structures (which evolved to nano-tendrils at higher fluences), which we could not see in the sample tilted $\left(52^{\circ}\right)$ case (Fig. 1). Figure 3 also shows an enhancement in the hole size broadening with increasing the $\mathrm{He}^{+}$ion fluence. The enhancement in the hole size may be understood in the realm of coalescence between the adjacent holes. Such coalescence is evidenced by hole shape transformation from smaller (Fig. 3(a)) to bigger and irregular shape (Figs. 3(b) - (d)). At the same time, thinning of the walls (that separate these holes) is also noticeable. Considering the "surface nano-feature vertical growth" between these nanoscopic holes, as observed in the sample tilting case (Fig. 1), it is clear now that the "excess materials," which results from the "growth" and the "coalescence" of the surface holes, migrate upward and cause the out-of-plane nanostructure growth.

Similar nanscopic holes after high fluence He plasma exposures on W surfaces were also previously reported by several researchers [32, 44, 45]. The hypothesis suggested by Kajita et al. [2] is more relevant for explaining the pinhole formation in our study. In their hypothesis, they rely on the localized temperature gradient that might be formed within the $\mathrm{W}$ sub surface region due to the presence of progressively growing He bubbles. Our results show similar surface 
pinhole formation phenomena. The role of He bubbles formation and growth, within the lattice of irradiated W, may be another anticipated factor, for such surface morphology evolutions on W surfaces due to low energy $\mathrm{He}^{+}$ion irradiations [5]. Further, in the evolutions of such ultra-fine W-fuzz structures, the surface energy has a significant role over the other energies due to the large surface to volume ratio. This explains the unfeasibility to find naturally grown fuzz structure for any metallic system. Another possibility for such structural transformation, disregarding the surface energy constraints, may be the recrystallization phenomena.

The final stage that can lead to formation of the nano-structure is the surface diffusion and the redistribution of the newly arrived surface atoms (i.e., the self-interstitials). These atoms may arrive and set singly on the top surface. In this situation, these surface atoms will have a minimal binding energy and they are susceptible to diffuse freely on the top surface. The experimental observation confirms the progressive growth of only small part of the surface to form the nanotendril structure. We assume that the tip of these nano-tendrils is the preferred destination for the surface $\mathrm{W}$ diffused atoms. In an intense surface diffusion situation, any local increase of the surface binding energy in some surface spots will create a net-flow of atoms toward these spots and allow them to grow.

The chemical composition of irradiated sample has also been monitored from XPS, in in-situ condition. As shown in Fig. 4, the XPS spectrum shows a pure W peaks with no contamination. We only noticed a minor oxygen peak [46] at $530 \mathrm{eV}$ as can be seen in Fig. 4(a). This minor oxygen presence in the surface is most likely due to some water adsorption on the target surface occurred after the irradiation process [47]. High resolution XPS of the W-4f region (Fig. 4(b)) confirms the absence of $\mathrm{W}$ - oxide and supports our conclusion that the presence of oxygen was due to water adsorption. In this region only peaks of pure state of $\mathrm{W}$ were found. The $\mathrm{W} 4 \mathrm{f} 7 / 2$ 
was found to be situated at $31.4 \mathrm{eV}$, while the $\mathrm{W} 4 \mathrm{f}_{5 / 2}$ was positioned at $33.57 \mathrm{eV}$. These values were found to be in agreement with most accepted peaks values for pure state of W [46].

\section{b. Effect of $\mathrm{He}^{+}$ion flux}

Three additional $\mathrm{W}$ samples were prepared in similar condition and irradiated by $300 \mathrm{eV} \mathrm{He}^{+}$ion beam using $2.0 \times 10^{20}, 3.2 \times 10^{20}, 5.5 \times 10^{20}$ ions $\mathrm{m}^{-2} \mathrm{~s}^{-1}$ fluxes. Other irradiation parameters such as sample temperature $\left(900^{\circ} \mathrm{C}\right)$ and $\mathrm{He}^{+}$ion fluence $\left(1 \times 10^{25}\right.$ ions $\left.\mathrm{m}^{-2}\right)$ were kept constant for all the three samples. As evidenced, in SEM images (Fig. 5), and also in the physical appearance of the irradiated samples, W nano-tendrils growth increases with increasing $\mathrm{He}^{+}$flux. Despite the long irradiation time for the sample that was bombarded by low ion flux $\left(2.0 \times 10^{20}\right.$ ions $\mathrm{m}^{-2} \mathrm{~s}^{-1}$ ) the sample surface after irradiation shows very fade darkening (almost no change). Moreover, the nanostructure of the irradiated surface was found to be still in the very early stages of fuzz formation as shown in Fig. 5 (a).

Increasing the $\mathrm{He}^{+}$ion flux to $\left(3.2 \times 10^{20}\right.$ ions $\left.\mathrm{m}^{-2} \mathrm{~s}^{-1}\right)$ cause a noticeable darkening in the sample fuzz region. The surface SEM images confirm the growth of $\mathrm{W}$ fuzz in this region as shown in Fig. 5(b). The third sample confirms the trend of flux dependent $\mathrm{W}$ fuzz growth rate. This sample was irradiated at higher flux $\left(5.5 \times 10^{20}\right.$ ions $\left.\mathrm{m}^{-2} \mathrm{~s}^{-1}\right)$ for shorter period. The irradiated sample surface was darker than the previous two samples. Moreover, the $\mathrm{W}$ fuzz was found to be more advanced and much finer than the previous cases as shown in Fig. 5(c).

In addition to the $\mathrm{He}^{+}$ion fluence dependency of the $\mathrm{W}$ fuzz evolution phenomenon, the $\mathrm{He}^{+}$ions flux found to have an important role. Higher $\mathrm{He}^{+}$ion flux results more fuzz growth and vice versa. We believe that helium flux governs the rate of nano-tendril's growth by two main roles; the first one can be understood in the realm of the fact that $\mathrm{He}^{+}$ion flux is the most important 
factor that determines the He concentration in the $\mathrm{W}$ subsurface lattice during irradiation. This concentration as we believe should be much higher than the equilibrium solubility limit of the $\mathrm{W}$ lattice. Thus, nucleation and growth of helium bubbles is the expected response to reduce Helium concentration from W lattice. Hence, Ion flux is the parameter that governs the internal $\mathrm{He}$ pressure in the He bubbles. Therefore, the He bubbles internal pressure dictates the rate of selfinterstitials emission which in turn determines the rate of fuzz growth.

The second role can be understood from the role of high helium lattice concentration in slowing down or jamming the $\mathrm{W}$ self-diffusion process. We believe that the presence of high concentration of He within the $\mathrm{W}$ lattice will jam and freeze the $\mathrm{W}$ atoms self-diffusion process. The self-diffusion process mostly occurs when a lattice atom jumps into a vacant site. Therefore, it is hard to imagine the presence of vacant lattice sites within a supersaturated $\mathrm{W}$ structure. Instead, all the vacant sites will be filled with multiple He atoms (He-vacancies complexes). This He occupation will restrict the jumping of the $\mathrm{W}$ atoms into the occupied vacant site. Thus, selfdiffusion process will be largely parallelized in high flux Helium ions irradiation situation. This hypothesis of jammed $\mathrm{W}$ self-diffusion is necessary to explain the stability of the surface elongated features (with large interfacial energy) such as the $\mathrm{W}$ nano-tendrils during the $\mathrm{He}^{+}$ion bombardment. Otherwise, a backward bulk diffusion process is expected to initiate an internal backward flow of $\mathrm{W}$ atoms from the tip of nano-fiber toward its root to minimize the increasing surface energy of the system. This trend of reversible flow was confirmed by annealing of the fuzzy W surface to a high temperature in absence of Helium irradiation. Hence, obvious reduction in the W-fuzz height was reported[48-50].

The observation of reduction in $\mathrm{W}$ - fuzz thickness after annealing is very useful as it leads us to the fact that, W-fuzz structure is a thermodynamically unstable structure. Therefore, it has the 
ability (upon being thermally activated to enhance the self-diffusion process) to reverse itself to lower its total free energy. The unstable pure metallic structures appear either when the transformation is too fast, or when the self-diffusion process is too slow to maintain the possible minimum free energy. In fact, the transformation of the $\mathrm{W}$ sample from a smooth to fuzzy surface is a slow process, and is developed over relatively long time. Therefore, $\mathrm{W}$ self-diffusion process must be significantly slow during the He irradiation process. This agrees with our hypothesis of the role He concentration within the W-lattice in mitigating the W self-diffusion process during irradiation. This He concentration that we believe, it is being dictated by the helium ion flux.

It is worthwhile to mention that, the ion flux used in the present study is nearly 0.5 times smaller than the typically used $\left(\sim 1 \times 10^{21}\right.$ ions $\left.\mathrm{m}^{-2} \mathrm{~s}^{-1}\right)$, to grow the fuzz structure surface modifications and pinholes because of He bubble formation[50]. However, in ITER, the ion flux can be of the order of $\sim 1 \times 10^{25}$ ions $\mathrm{m}^{-2} \mathrm{~s}^{-1}[50]$.

\section{c. Effect of $\mathrm{He}^{+}$ion energy}

To understand the effect of variation of ion beam flux profile (due to ion beam energy changes) on surface morphology, incident ion beam energy (at constant ion flux, fluence, and temperature) was varied and corresponding surface morphology changes was monitored, using SEM. The results were summarized in Fig. 6. For changing the incident ion beam energy, samples were positively biased using external power supply. Such sample biasing will generate an electrical field (in proportion to applied external voltage) which will decelerate the incident $\mathrm{He}^{+}$ions. The first sample was biased by $+160 \mathrm{~V}$ and therefore, the ions are expected to hit the surface by an incident energy equal to $140 \mathrm{eV}$. Although the samples were irradiated at high flux for 5 hours, the surface structure (nano-tendrils) (Fig. 7(a)) was found to be much shorter than what we 
usually see at the same irradiation fluence and flux when we bombard the surface by $300 \mathrm{eV} \mathrm{He}^{+}$ ions (Fig. 7(c)). The surface structures, after $200 \mathrm{eV}$ ion irradiations, grew to an intermediate stage that is somewhat in between the $300 \mathrm{eV}$ and the $140 \mathrm{eV}$ cases (Fig. 6(b)).

\section{Conclusion}

A series of pure $\mathrm{W}$ samples were irradiated by high fluxes of low energy $\mathrm{He}^{+}$ions for high fluences at $900^{\circ} \mathrm{C}$. The phenomenon of $\mathrm{He}^{+}$ion induced fuzz formation was observed in most of the irradiation cases. Several attempts were made to understand such fuzz formation by varying several irradiation parameters, viz. fluence, flux, and energy of incidence $\mathrm{He}^{+}$ions. The role of $\mathrm{He}^{+}$ion irradiation fluence was studied by varying the irradiation time duration for each sample. Surface pinholes and nano-tendril structure (fuzz) appearance, at a very early stage, were observed. By increasing $\mathrm{He}^{+}$ion fluence, these surface features evolved progressively to form what it appears to be an expanded surface holes and taller nano-tendrils before its further evolution to a W fuzz structure. Our study shows that W fuzz growth rate depends strongly on ion flux. This finding was confirmed in another irradiation experiments, where $\mathrm{W}$ samples were irradiated for the same ion fluence but with different ion fluxes. In these experiments, the W fuzz found to grow faster at higher He ion fluxes. Understanding various mechanisms responsible for surface morphology changes as well as possible mitigation techniques are very important for the reliability and performance of plasma-facing components in future fusion devices.

\section{Acknowledgment}


This work is supported the U.S. DOE, Office of Fusion Energy Sciences (OFES) and the

National Science Foundation, PIRE project. The authors acknowledge the help from O. ElAtwani in performing the SEM imaging.

\section{References}

[1] M. Roedig, W. Kuehnlein, J. Linke, M. Merola, E. Rigal, B. Schedler, E. Visca, Investigation of tungsten alloys as plasma facing materials for the ITER divertor, Fusion Engineering and Design 61-62 (2002) 135.

[2] S. Kajita, W. Sakaguchi, N. Ohno, N. Yoshida, T. Saeki, Formation process of tungsten nanostructure by the exposure to helium plasma under fusion relevant plasma conditions, Nucl. Fusion 49(9) (2009) 095005.

[3] Y. Fukai, The Metal-Hydrogen System Basic Bulk Properties, Springer-Verlag, Berlin Heidelberg, 2005.

[4] N. Noda, V. Philipps, R. Neu, A review of recent experiments on W and high Z materials as plasma-facing components in magnetic fusion devices, J. Nucl. Mater. 241-243 (1997) 227.

[5] M.J. Baldwin, R.P. Doerner, Helium induced nanoscopic morphology on tungsten under fusion relevant plasma conditions, Nucl. Fusion 48(3) (2008) 035001.

[6] M.J. Baldwin, R.P. Doerner, Formation of helium induced nanostructure 'fuzz' on various tungsten grades, J. Nucl. Mater. 404(3) (2010) 165-173. 
[7] M. Miyamoto, D. Nishijima, Y. Ueda, R.P. Doerner, H. Kurishita, M.J. Baldwin, S. Morito, K. Ono, J. Hanna, Observations of suppressed retention and blistering for tungsten exposed to deuterium-helium mixture plasmas, Nucl. Fusion 49(6) (2009) 065035.

[8] G.M. Wright, D. Brunner, M.J. Baldwin, K. Bystrov, R.P. Doerner, B. Labombard, B. Lipschultz, G. De Temmerman, J.L. Terry, D.G. Whyte, K.B. Woller, Comparison of tungsten nano-tendrils grown in Alcator C-Mod and linear plasma devices, J. Nucl. Mater. 438 (2013) S84-S89.

[9] S. Takamura, N. Ohno, D. Nishijima, S. Kajita, Formation of Nanostructured Tungsten with Arborescent Shape due to Helium Plasma Irradiation, Plasma and Fusion Research 1 (2006) 051-051.

[10] D. Nishijima, M.Y. Ye, N. Ohno, S. Takamura, Formation mechanism of bubbles and holes on tungsten surface with low-energy and high-flux helium plasma irradiation in NAGDIS-II, J. Nucl. Mater. 329-333 (2004) 1029-1033.

[11] H. Iwakiri, K. Yasunaga, K. Morishita, N. Yoshida, Microstructure evolution in tungsten during low-energy helium ion irradiation, J. Nucl. Mater. 283-287 (2000) 1134.

[12] G. Federici, P. Andrew, P. Barabaschi, J. Brooks, R. Doerner, A. Geier, A. Herrmann e, G. Janeschitz, K. Krieger, A. Kukushkin, A. Loarte, R. Neu, G. Saibene, M. Shimada, G. Strohmayer, M. Sugihara, Key ITER plasma edge and plasma-material interaction issues, J. Nucl. Mater. 313-316 (2003) 11. 
[13] G.M. Wright, D. Brunner, M.J. Baldwin, R.P. Doerner, B. Labombard, B. Lipschultz, J.L. Terry, D.G. Whyte, Tungsten nano-tendril growth in the Alcator C-Mod divertor, Nucl. Fusion 52(4) (2012) 042003.

[14] Y. Ueda, K. Miyata, Y. Ohtsuka, H.T. Lee, M. Fukumoto, S. Brezinsek, J.W. Coenen, A. Kreter, A. Litnovsky, V. Philipps, B. Schweer, G. Sergienko, T. Hirai, A. Taguchi, Y. Torikai, K. Sugiyama, T. Tanabe, S. Kajita, N. Ohno, Exposure of tungsten nano-structure to TEXTOR edge plasma, J. Nucl. Mater. 415(1) (2011) S92-S95.

[15] J.N. Brooks, J.P. Allain, R.P. Doerner, A. Hassanein, R. Nygren, T.D. Rognlien, D.G. Whyte, Plasma-surface interaction issues of an all-metal ITER, Nucl. Fusion 49(3) (2009) 035007.

[16] T.J. Dolan, Fusion research: priciples, experiments and technology, Pergamon press, oxford, 1982.

[17] M. Tokitani, S. Kajita, S. Masuzaki, Y. Hirahata, N. Ohno, T. Tanabe, Exfoliation of the tungsten fibreform nanostructure by unipolar arcing in the LHD divertor plasma, Nucl. Fusion 51(10) (2011) 102001.

[18] K.B. Woller, D.G. Whyte, G.M. Wright, D. Brunner, Experimental investigation on the effect of surface electric field in the growth of tungsten nano-tendril morphology due to low energy helium irradiation, J. Nucl. Mater. 481 (2016) 111-116.

[19] M. Baldwin, T. Lynch, R. Doerner, J. Yu, Nanostructure formation on tungsten exposed to low-pressure rf helium plasmas: a study of ion energy threshold and early stage growth, J. Nucl. Mater. 415(1) (2011) S104-S107. 
[20] G. De Temmerman, K. Bystrov, J.J. Zielinski, M. Balden, G. Matern, C. Arnas, L. Marot, Nanostructuring of molybdenum and tungsten surfaces by low-energy helium ions, J. of Vac. Sci. Technol. A 30(4) (2012) 041306.

[21] G. Wright, D. Brunner, M. Baldwin, R. Doerner, B. Labombard, B. Lipschultz, J. Terry, D. Whyte, Tungsten nano-tendril growth in the Alcator C-Mod divertor, Nucl. Fusion 52(4) (2012) 042003.

[22] V. Voitsenya, A. Bardamid, V. Bondarenko, W. Jacob, V. Konovalov, S. Masuzaki, O. Motojima, D. Orlinskij, V. Poperenko, I. Ryzhkov, Some problems arising due to plasmasurface interaction for operation of the in-vessel mirrors in a fusion reactor, J. Nucl. Mater. 290 (2001) 336-340.

[23] G. De Temmerman, R. Pitts, V. Voitsenya, L. Marot, G. Veres, M. Maurer, P. Oelhafen, First mirror tests for ITER: Influence of material choice on the erosion/deposition mechanisms affecting optical reflectivity, J. Nucl. Mater. 363 (2007) 259-263.

[24] A. Litnovsky, P. Wienhold, V. Philipps, G. Sergienko, O. Schmitz, A. Kirschner, A. Kreter, S. Droste, U. Samm, P. Mertens, A.H. Donné, D. Rudakov, S. Allen, R. Boivin, A. McLean, P. Stangeby, W. West, C. Wong, M. Lipa, B. Schunke, G. De Temmerman, R. Pitts, A. Costley, V. Voitsenya, K. Vukolov, P. Oelhafen, M. Rubel, A. Romanyuk, Diagnostic mirrors for ITER: A material choice and the impact of erosion and deposition on their performance, J. Nucl. Mater. 363-365 (2007) 1395-1402.

[25] T. Nakano, M. Miyamoto, S. Hasuike, K. Ono, N. Yoshida, Degradation of optical properties in Mo mirrors under irradiation with low energy helium and deuterium ions, J. Nucl. Mater. 417(1) (2011) 834-837. 
[26] A. Ebihara, M. Tokitani, K. Tokunaga, T. Fujiwara, A. Sagara, N. Yoshida, Irradiation effects of low energy helium ions on optical reflectivity of metallic mirror, J. Nucl. Mater. 363 (2007) 1195-1200.

[27] V. Voitsenya, A. Bardamid, V. Gritsyna, V. Konovalov, O. Motojima, D. Orlinskij, R. Palladino, B. Peterson, A. Shapoval, A. Shtan, On the choice of materials for the first mirrors of plasma diagnostics in a fusion reactor, J. Nucl. Mater. 258 (1998) 1919-1923.

[28] R.P. Doerner, M.J. Baldwin, P.C. Stangeby, An equilibrium model for tungsten fuzz in an eroding plasma environment, Nucl. Fusion 51(4) (2011) 043001.

[29] S. Sharafat, A. Takahashi, Q. Hu, N.M. Ghoniem, A description of bubble growth and gas release of helium implanted tungsten, J. Nucl. Mater. 386-388 (2009) 900-903.

[30] A. Lasa, S.K. Tähtinen, K. Nordlund, Loop punching and bubble rupture causing surface roughening - A model for W fuzz growth, EPL (Europhysics Letters) 105(2) (2014) 25002.

[31] A. Lasa, K.O.E. Henriksson, K. Nordlund, MD simulations of onset of tungsten fuzz formation under helium irradiation, Nucl. Instr. and Meth. in Phys. Res. B 303 (2013) 156161.

[32] N. Yoshida, H. Iwakiri, K. Tokunaga, T. Baba, Impact of low energy helium irradiation on plasma facing metals, J. Nucl. Mater. 337-339 (2005) 946-950.

[33] R. Sakamoto, T. Muroga, N. Yoshida, Microstructural evolution induced by low energy hydrogen ion irradiation in tungsten, J. Nucl. Mater. 220-222 (1995) 819. 
[34] H. Iwakiri, K. Yasunaga, K. Morishita, N. Yoshida, Microstructure evolution in tungsten during low-energy helium ion irradiation, Journal of Nuclear Materials 283-287 (2000) 1134.

[35] M. Nastasi, J.W. Mayer, J.K. Hirvonen, Ion-solid interactions: fundamentals and applications, Cambridge university press, Cambridge, UK, 1996.

[36] S. Kajita, D. Nishijima, N. Ohno, S. Takamura, Reduction of laser power threshold for melting tungsten due to subsurface helium holes, J. Appl. Phys. 100(10) (2006) 103304.

[37] J.H. Evans, Breakaway bubble growth during the annealing of helium bubbles in metals, J. Nucl. Mater. 334(1) (2004) 40-46.

[38] S.E. Donnelly, The density and pressure of helium in bubbles in implanted metals: A critical review, Radiation Effects 90(1-2) (1985) 1-47.

[39] J.H. Evans, A.v. Veen, L.M. Caspers, In-situ TEM observations of loop punching from helium platelet cavities in molybdenum, Scripta Metallurgica 17 (1983) 549.

[40] D. Nishijima, H. Iwakiri, K. Amano, M.Y. Ye, N. Ohno, K. Tokunaga, N. Yoshida, S. Takamura, Suppression of blister formation and deuterium retention on tungsten surface due to mechanical polishing and helium pre-exposure, Nucl. Fusion 45(7) (2005) 669-674.

[41] F. Sefta, N. Juslin, B.D. Wirth, Helium bubble bursting in tungsten, J. Appl. Phys. 114(24) (2013) 243518.

[42] M.Y. Ye, H. Kanehara, S. Fukuta, N. Ohno, S. Takamura, Blister formation on tungsten surface under low energy and high flux hydrogen plasma irradiation in NAGDIS-I, J. Nucl. Mater. 313-316 (2003) 72. 
[43] J.P. Allain, M. Nieto, M.R. Hendricks, P. Plotkin, S.S. Harilal, A. Hassanein, IMPACT: A facility to study the interaction of low-energy intense particle beams with dynamic heterogeneous surfaces, Rev. Sci. Instrum. 78(11) (2007) 113105.

[44] B.B. Cipiti, G.L. Kulcinski, Helium and deuterium implantation in tungsten at elevated temperatures, J. Nucl. Mater. 347(3) (2005) 298-306.

[45] S.J. Zenobia, L.M. Garrison, G.L. Kulcinski, The response of polycrystalline tungsten to $30 \mathrm{keV}$ helium ion implantation at normal incidence and high temperatures, J. Nucl. Mater. 425(1-3) (2012) 83-92.

[46] J. Moulder, F., W. Stickle, F., P. Sobol, E., K. Bomben, D. , Handbook of X-ray Photoelectron Spectroscopy, Perkin-Elmer Corporation; Physical Electronics Division, Eden Prairie, Minosota, USA 1992.

[47] A.B. Al-Ajlony, A. Kanjilal, S.S. Harilal, A. Hassanein, Carbon contamination and oxidation of $\mathrm{Au}$ surfaces under extreme ultraviolet radiation: An x-ray photoelectron spectroscopy study, J. Vac. Sci. Technol. B. 30(4) (2012) 041603.

[48] S. Takamura, T. Miyamoto, Y. Tomida, T. Minagawa, N. Ohno, Investigation on the effect of temperature excursion on the helium defects of tungsten surface by using compact plasma device, J. Nucl. Mater. 415(1, Supplement) (2011) S100-S103.

[49] Y. Wu, L. Liu, B. Lu, W. Ni, D. Liu, W nano-fuzzes: A metastable state formed due to large-flux He+ irradiation at an elevated temperature, J. Nucl. Mater. 482 (2016) 294-299. 
[50] S. Kajita, N. Ohno, M. Yajima, J. Kato, Growth annealing equilibrium of tungsten nanostructures by helium plasma irradiation in non-eroding regimes, J. Nucl. Mater. 440(13) (2013) 55-62. 


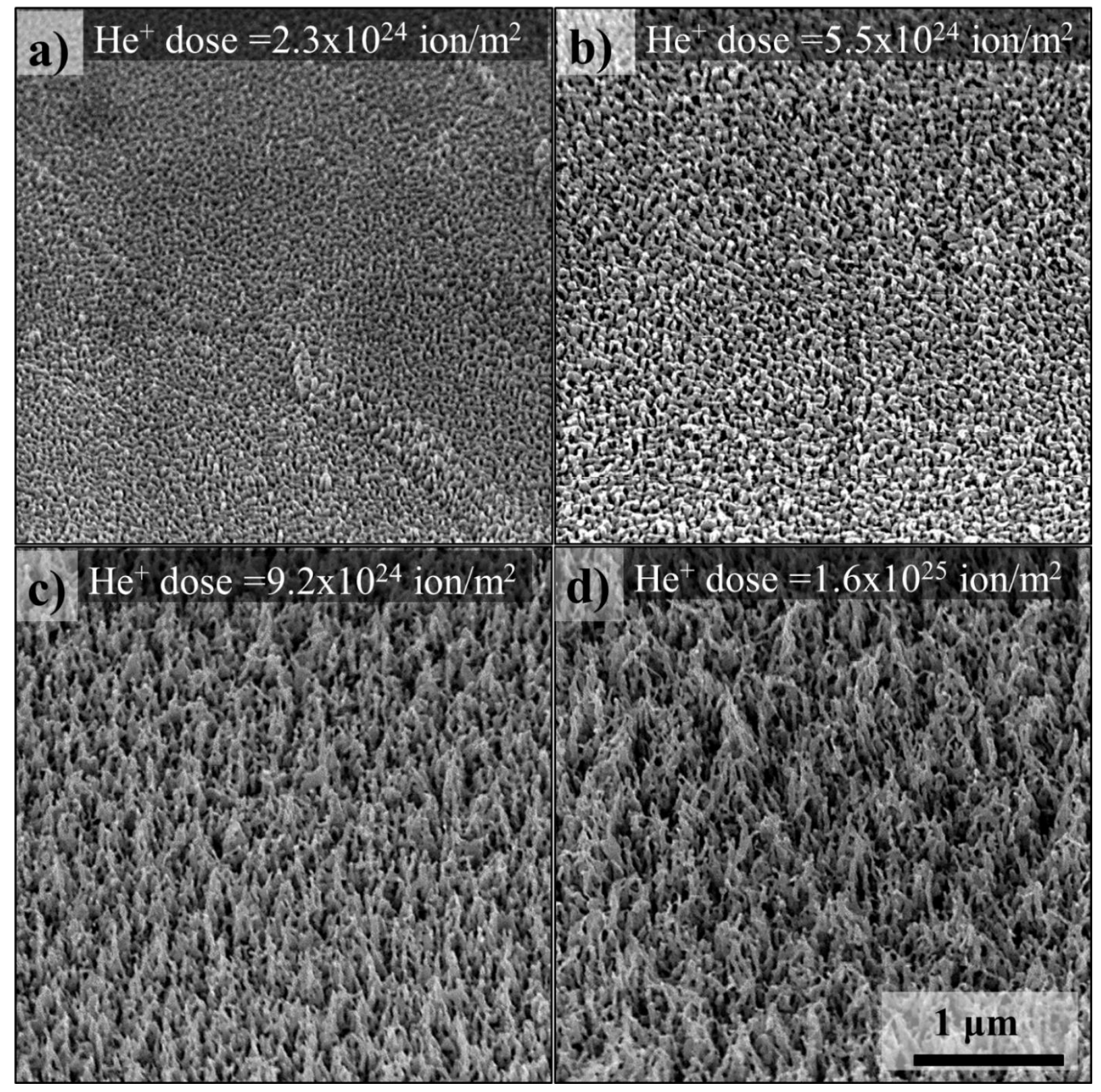

Fig. 1. SEM images of nanostructure formed in the samples dark regions, all samples were bombarded by $300 \mathrm{eV}$ of He ions (flux $=5.5 \times 10^{20}$ ions $\mathrm{m}^{-2} \mathrm{~s}^{-1}$ at the sample center) for different irradiation fluence per each sample, the SEM images taken at angle of view of $52^{\circ}$. The irradiation fluences that had been received for each sample are: $2.3 \times 10^{24}$ ions $\mathrm{m}^{-2}(\mathrm{a}), 5.5 \times$ $10^{24}$ ions $\mathrm{m}^{-2}(\mathrm{~b}), 9.2 \times 10^{24}$ ions $\mathrm{m}^{-2}(\mathrm{c})$, and $1.6 \times 10^{25}$ ions $\mathrm{m}^{-2}(\mathrm{~d})$ 


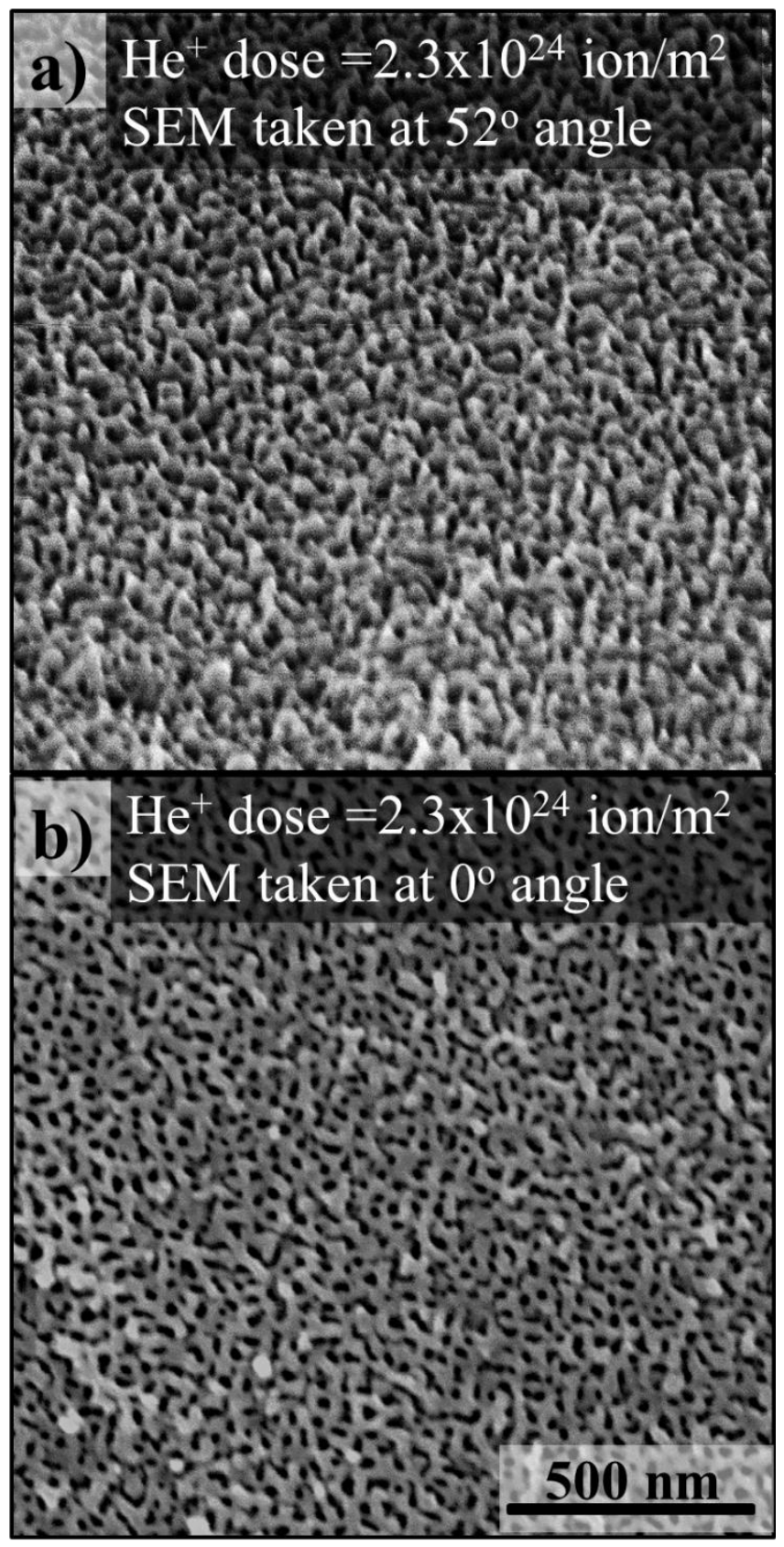

Fig. 2. SEM images at various angles of views showing the main differences in a nanostructure appearance. , the sample was bombarded by $300 \mathrm{eV}$ of He ions (flux $=5.5 \times 10^{20}$ ions $\mathrm{m}^{-2} \mathrm{~s}^{-1}$ ) for a fluence of $2.3 \times 10^{24}$ ions $\mathrm{m}^{-2}$. The SEM images were taken at $52^{\circ}$ (a), and at $0^{\circ}$ (top view) (b). 


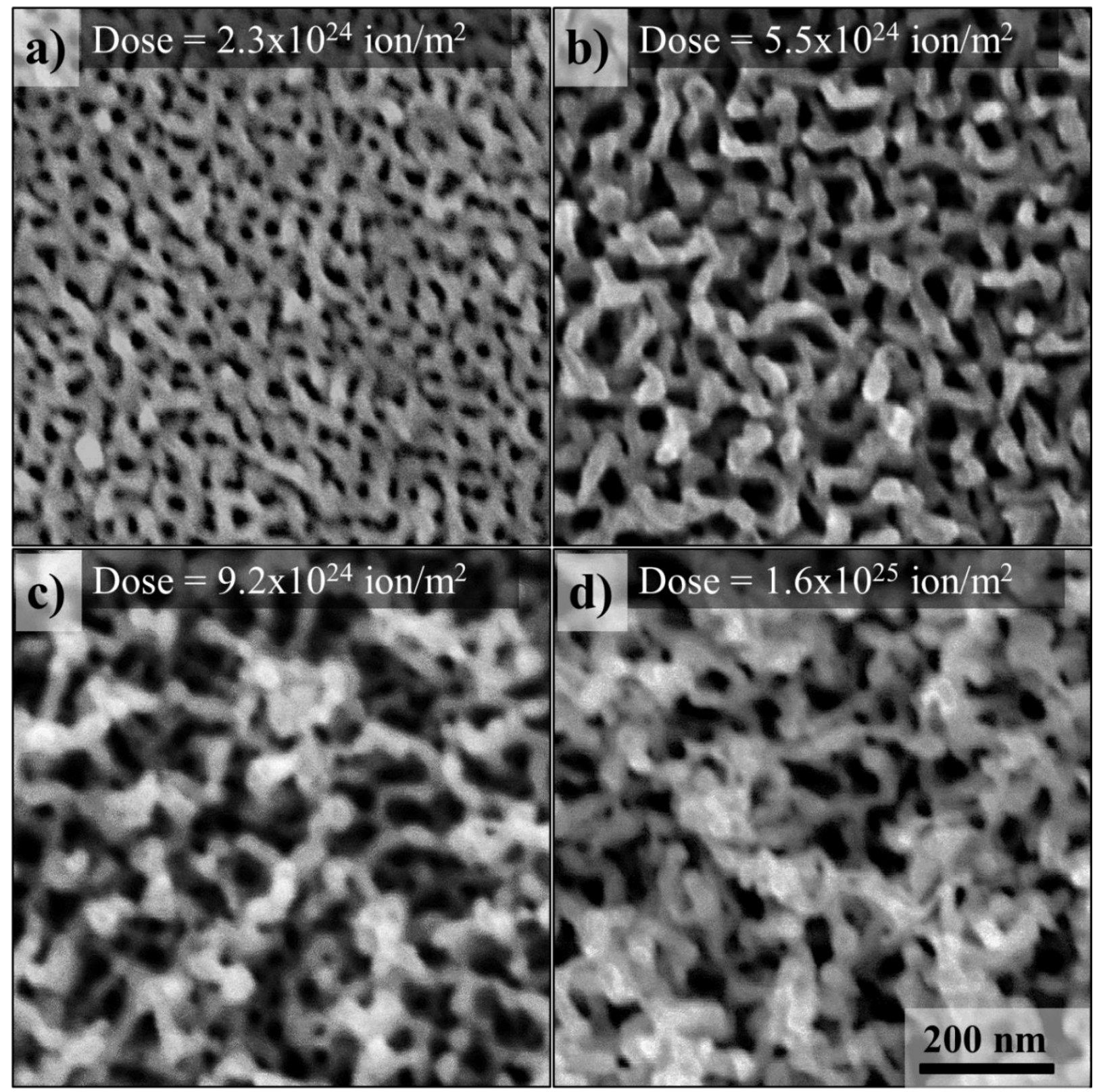

Fig. 3. SEM images of nanostructure formed in the samples dark regions (fuzzy structured regions) all the samples were bombarded by $300 \mathrm{eV}$ of He ions (flux $=5.5 \times 10^{20}$ ions $\mathrm{m}^{-2} \mathrm{~s}^{-1}$ ) for different irradiation fluence per each sample, the SEM images taken at angle of view of $0^{\circ}$. The irradiation fluences that had been received by each sample are: $2.3 \times 10^{24}$ ions $^{-2}(\mathrm{a}), 5.5 \times 10^{24}$ ions $\mathrm{m}^{-2} \mathrm{~s}^{-1}(\mathrm{~b}), 9.2 \times 10^{24}$ ions $\mathrm{m}^{-2} \mathrm{~s}^{-1}(\mathrm{c})$, and $1.6 \times 10^{25}$ ions $\mathrm{m}^{-2} \mathrm{~s}^{-1}(\mathrm{~d})$ 

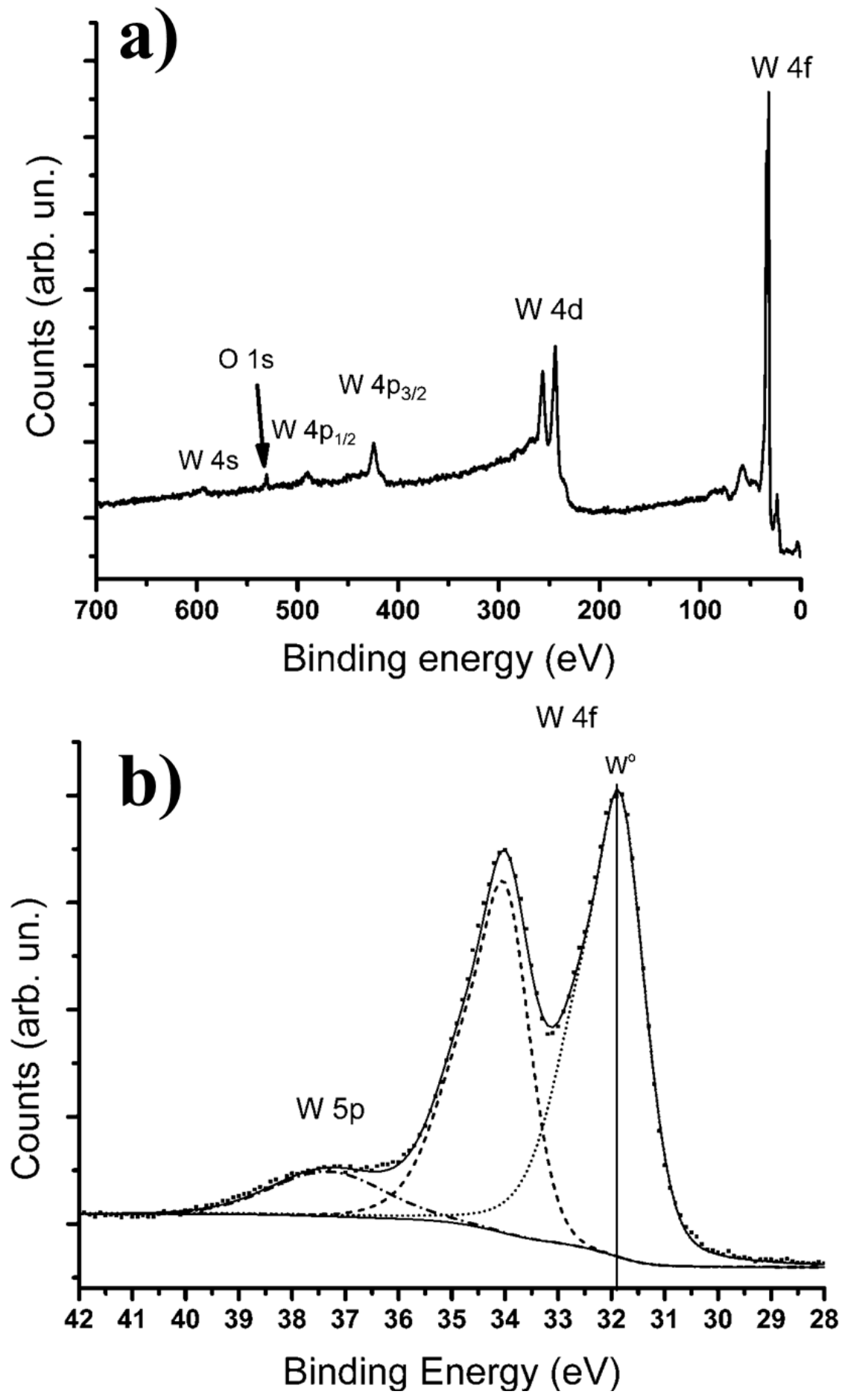

Fig. 4. XPS full spectrum (a), and high resolution XPS spectrum for the $\mathrm{W} 4 \mathrm{f}$ region (b). 


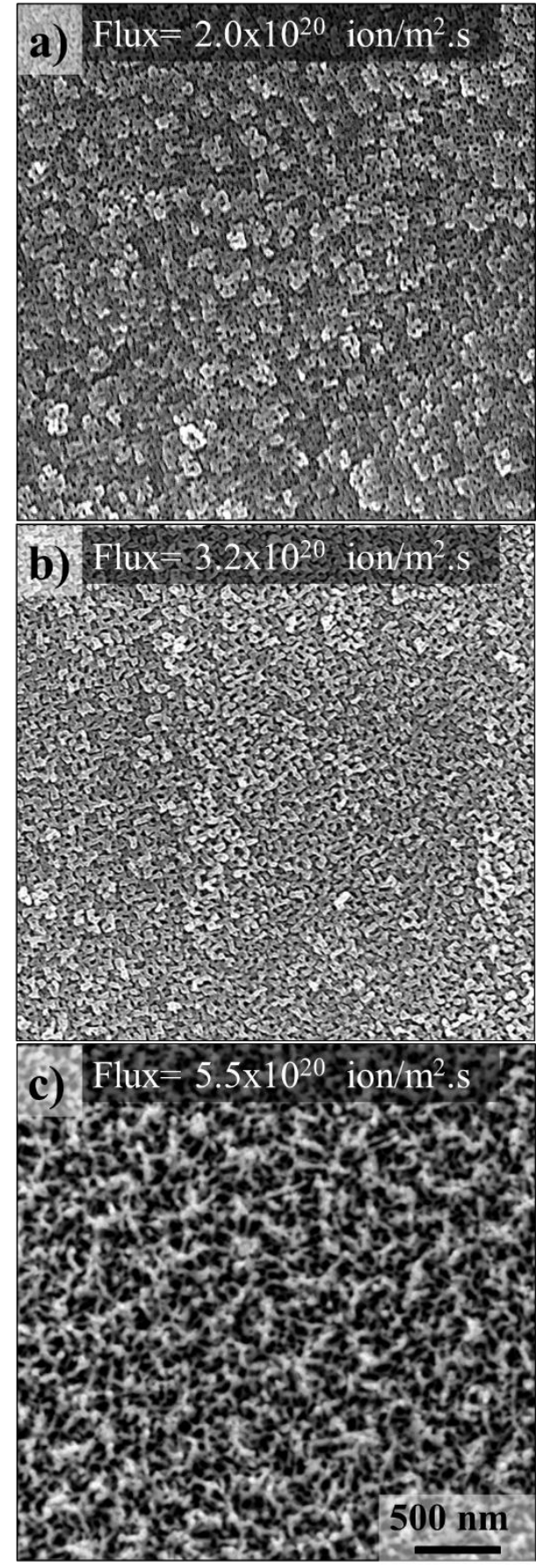

Fig. 5. SEM images of nanostructure formed in the samples. The samples were bombarded by $300 \mathrm{eV}$ of $\mathrm{He}$ ions (fluence $=1 \times 10^{25}$ ions $\mathrm{m}^{-2} \mathrm{~s}^{-1}$ ) at a samples temperature of $900^{\circ} \mathrm{C}$. The ion beam flux was varied for each sample as well as the irradiation times. The ion beam fluxes that was selected for each sample are: $2.0 \times 10^{20}$ ions $\mathrm{m}^{-2} \mathrm{~s}^{-1}(\mathrm{a}), 3.2 \times 10^{20}$ ions $\mathrm{m}^{-2} \mathrm{~s}^{-1}$ (b), and $5.5 \times$ $10^{20}$ ions $\mathrm{m}^{-2} \mathrm{~s}^{-1}(\mathrm{c})$ 


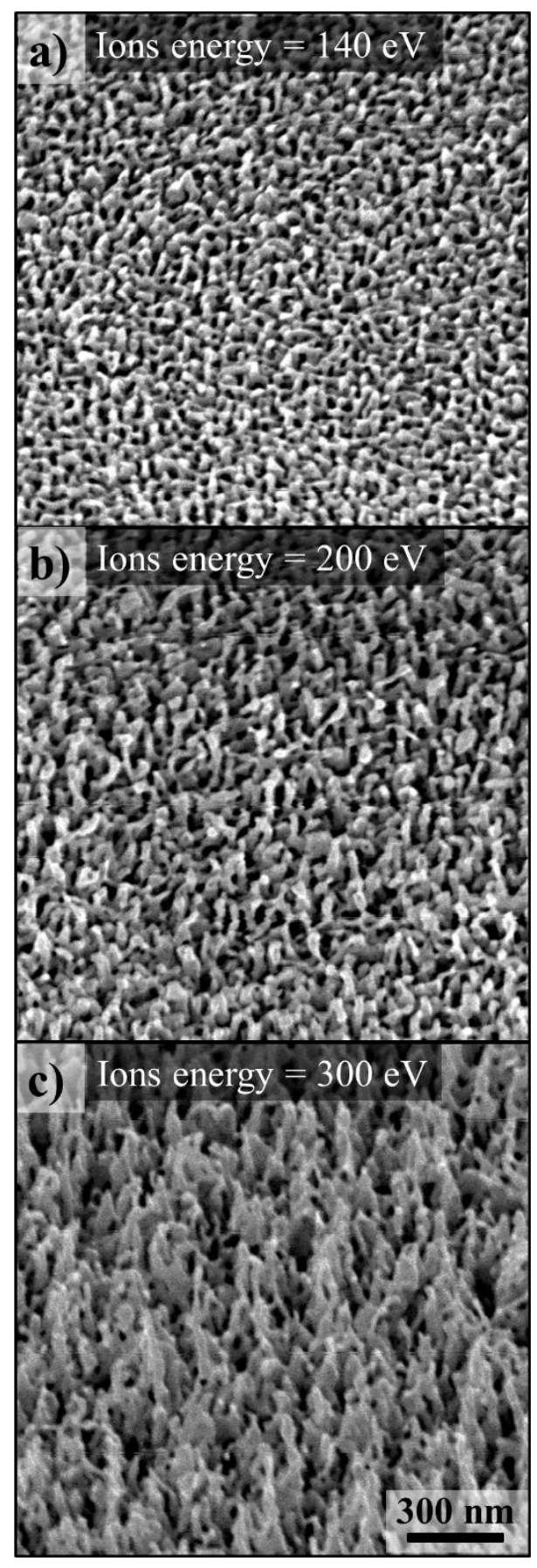

Fig. 6. SEM images of nanostructure formed in the samples. The samples were bombarded by He ions (fluence $=1 \times 10^{25}$ ions $\mathrm{m}^{-2} \mathrm{~s}^{-1}$ and flux $=5.5 \times 10^{20}$ ions $\mathrm{m}^{-2} \mathrm{~s}^{-1}$ ). Samples temperature during irradiation was fixed at $900^{\circ} \mathrm{C} . \mathrm{He}^{+}$ion incident energy was varied for each sample by applying positive bias voltage. $\mathrm{He}^{+}$ion incident energies that were selected are: $140 \mathrm{eV}$ (a), 200 $\mathrm{eV}$ (b) and $300 \mathrm{eV}$ (c). The SEM images were taken at $52^{\circ}$ sample tilt. 